\title{
The construction of an experimental prestressed concrete road at Winthorpe, Nottinghamshire
}

\author{
R. A. KIDD \& J. P. STOTT
}

\section{Mr R. A. Kidd and Dr J. P. Stott}

As members of an international committee set up for the purpose of studying the use of prestressing in the construction of roads we were much impressed by the extent of work which had been undertaken in some European countries. Some continental engineers have advanced beyond the experimental stage, particularly in the application of prestressing to slabs in airfield runways.

45. Of the two main methods of the application of prestress, namely using stressing cables and using ground anchorages and hydraulic jacks, we selected the latter, which minimizes the degree of manual operation. The other process seems somewhat inconsistent with the trend to mechanization when high output of concrete batching, mixing, transportation, placing and finishing is possible, but is followed by the slow manual operation of stressing by cable with a very large labour force.

46. Is there really any future in prestressing road slabs? We suggest it cannot yet be claimed that this is so, but in the experimental road a great deal has been learned about the technique and all the factors involved, including creep of concrete and loss of prestress.

\section{Mr E. Lock, Road Research Laboratory}

I was in charge of the construction of the prestressed concrete road at Winthorpe, and subsequently of maintaining observation and periodic restressing. In the first stage the active joint is completely blocked, the blocking concrete being cast in sections between the dowel bars. The next stage is to remove half of the blocking concrete, leaving alternate sockets empty. Jacks are then placed in the empty sockets, the joint is forced open, and most of the remaining concrete is removed and replaced by more jacks. The amount of prestress required to be applied to the joint is measured by a pressure gauge in the jacking pipeline.

48. At this stage the full designed value of the prestress, i.e., a stress of $300 \mathrm{lb} /$ sq. in. at $-10^{\circ} \mathrm{C}$ is applied, allowing $200 \mathrm{lb} / \mathrm{sq}$. in. for subgrade friction, and giving a minimum stress of $100 \mathrm{lb} / \mathrm{sq}$. in. at the farthest point from the stressing joint. For every $1^{\circ} \mathrm{C}$ rise in temperature from $-10^{\circ} \mathrm{C}$, a further $70 \mathrm{lb} / \mathrm{sq}$. in. is necessary, so that at $10^{\circ} \mathrm{C}$ a stress of $1700 \mathrm{lb} / \mathrm{sq}$. in. is applied.

49. As a further check on the applied stress, the joint opening is measured. The jacks are progressively removed and replaced by $1 \frac{1}{4}$ in. dia. nuts and bolts used as pillar jacks. The joint is held open purely by the nuts and bolts. The remaining empty sockets are then filled with concrete, mixed with a rapid hardening cement, which attains $4000 \mathrm{lb} / \mathrm{sq}$. in. compressive strength at only $16 \mathrm{~h}$. After this concrete has set, further nuts and bolts are removed and more concrete placed in the joint until the joint is completely blocked.

50. At the commencement of work at Winthorpe, steel envelope flat-jacks were used for prestressing. The size of these jacks was such as to fit into the prestressing joint between dowel bars giving the maximum area of contact, 14 jacks to each joint.

Paper published: Proc. Instn civ. Engrs, 1967, 36 (March) 473-498. 
These jacks will give approximately $1 \frac{1}{4} \mathrm{in}$. displacement, and several operations of packing the joints and reshaping the jacks were necessary to obtain the required prestress. Although considerable help was received from the suppliers of these jacks, the design was such that the prestress required could not be achieved if the road temperature rose a few degrees above freezing point, as the maximum prestress which they could apply was $800 \mathrm{lb} / \mathrm{sq}$. in. with a hydraulic pressure in the jacks of $2000 \mathrm{lb} / \mathrm{sq}$. in. In addition, the jacks developed a large number of fatigue splits along the braised joints with the repeated extensions and compressions, for which they were not originally designed.

51. It was therefore only possible to apply the design stress during the winter, which imposes a severe limitation on this type of construction. Some cheap piston jacks were then designed by the RRL. The construction of these was kept as simple as possible and consisted of a 3 in. length of high tensile steel tubing with one end blanked off with a thin metal plate, as the end of the jack receives support from the joint face; a loose-fitting piston with a proprietory sealing ring made the moving plunger. The internal bore of the tube is $4 \mathrm{in}$. and the wall $\frac{1}{2}$ in. thick. This allows four jacks to be placed between pairs of dowel bars and a total of 56 jacks can be used for prestressing one joint. With this type of jack, with a working pressure in the oil pipeline of $6000 \mathrm{lb} / \mathrm{sq}$. in., it was possible to apply prestress of $2500 \mathrm{lb} / \mathrm{sq}$. in. to the road, so that the design requirements could be met at almost any time throughout the year providing road temperatures in excess of about $20^{\circ} \mathrm{C}$ were avoided.

52. In future work, the prestressing equipment could perhaps be fitted to a specially constructed trailer which would open to span the road, each jack being fitted to a separate rubber hose and attached to a permanent pipeline on the trailer. The pumping equipment could be carried on the towing vehicle. With this, six men working under one foreman could work in the following manner. Two labourers working with a compressor and pneumatic drills would lead the team and remove half the concrete blocking from the joint to leave seven open sockets. They would then move forward to the next joint and repeat the process. The foreman and perhaps one or two fitters would insert jacks into this joint and apply sufficient prestress just to open the joint, thereby measuring the residual prestress. This figure would be of use to the engineer in assessing the performance of the road and calculating the loss of prestress due to creep, which would give him a guide to the frequency of further prestressing. The joint would then be opened further and all the blocking concrete removed. Sufficient jacks would be dropped into the joint to attain the required prestress. Previous calculations would be done relating prestress and temperature, and given to the foreman in the form of a table.

53. After applying the stress, the fitters would then progressively remove the jacks and replace them by the nut and bolt pillar jacks until the joint was held open by the nuts and bolts and four empty sockets left for concrete. The two remaining labourers would fill these sockets with concrete and again progressively remove bolts and replace with more concrete. These two men could work on a number of joints at the same time. If this method is adopted, it should be possible for a team of seven men to prestress three joints per day at $500 \mathrm{ft}$ spacing. This would enable the team to prestress a dual carriageway 3 miles long in 18 working days, and it would not be necessary for any section of the road to be closed for more than 4 days.

\section{Mr J. Broad, John Laing \& Son Limited}

The Authors are to be congratulated on a bold experiment. In the Paper's conclusions it is stated that a need to restress arose at yearly intervals; this would clearly be unacceptable in practice, and in any event, even with this degree of attention, the experimental road shows signs of cracking. One restress only might be acceptable and thus if the basic idea is to be pursued a possible solution would be a concrete of lower $E$ value and lower thermal coefficient.

55. The Laing Group manufactures an aggregate, Lytag, possessing such qualities. 
The thermal coefficient of Lytag concrete is almost half that of gravel concrete $\left(4 \times 10^{-6}\right.$ against $\left.7 \times 10^{-6}\right)$. It also has an $E$ value about half that of gravel and probably even less than some of the quartzite gravels $\left(2 \times 10^{6} \mathrm{lb} / \mathrm{sq}\right.$. in. against $4.5 \times 10^{6} \mathrm{lb} / \mathrm{sq}$. in.).

56. The idea of using Lytag has progressed beyond the theoretical stage, since a prominent Belgian company (Cimenteries Briqueteries Reunies) imported Lytag granular material in 1964 and constructed a road at Lier, similar to the Winthorpe road. It is nearly $400 \mathrm{yd}$ long and $5 \mathrm{in}$. thick, and a certain amount of limestone aggregate and sand was incorporated into the mix, mainly for reasons of cost; this would tend to make the $E$ value less advantageous than in an all-Lytag mix.

57. The prestressing was created by ordinary screw jacks and was begun very shortly after initial hardening, being gradually increased on succeeding days until a figure of $1820 \mathrm{lb} / \mathrm{sq}$. in. was reached. The subsequent history is of interest against the background of the Winthorpe experiment:

$\begin{array}{lc}\text { July, 1964 } & \text { lb/sq. in. } \\ \text { September, 1964 } & 1820 \\ \text { November, 1964 } & 1260 \\ \text { March, 1965 } & 1540 \\ \text { June, 1965 } & 1260\end{array}$

58. I heard from the Belgian engineer only a few days ago that the road continues to perform well and, as the figures indicate, shows no sign of cracking. It may require one further restress, although this has not so far been mentioned.

59. I know that the Authors are aware of the comparative success of the experimental road in Belgium, and view it with some favour. I should like to urge them or any other like-minded engineers to carry out further experiments in Britain with this indigenous material, which is readily available at reasonably low cost. I am sure that the group to which I belong would give them the fullest co-operation.

\section{Mr K. M. Brook, Cement and Concrete Association}

Having read the Paper it seems to me that the one outstanding snag in this type of construction is the creep effect of the concrete. I am sure that if this method of construction is to be adopted, there must be some form of pressure device which maintains a constant force on the concrete.

61. The one instance of which I know is a road in Switzerland where the pressure is maintained at a constant figure by two triangular slabs of concrete about half way along the road stressed transversely by cables, thus giving a wedge effect by pushing the two halves of the road against the abutments. The sloping sides of these triangular slabs maintain a constant pressure.

62. Turning to some of the results in the Paper, I was particularly interested in the graph given in Fig. 13 showing that the relation between the prestress and the temperature was $63 \mathrm{lb} / \mathrm{sq}$. in. per ${ }^{\circ} \mathrm{C}$. The Authors state that this relationship should be equal to the coefficient of expansion and the modulus of elasticity. If, however, the figures given in Table 2 relating to these properties (i.e. $10^{-5}$ in. for the coefficient of expansion and $5.05 \times 10^{6} \mathrm{lb} / \mathrm{sq}$. in. for the modulus of elasticity) are multiplied, the value comes out at only $50 \mathrm{lb} / \mathrm{sq}$. in. per ${ }^{\circ} \mathrm{C}$. I am surprised that the value of the coefficient of expansion is quoted as being as low as $1 \times 10^{-5}$ in./in. per ${ }^{\circ} \mathrm{C}$ as I would have expected a figure more of the order of say $1.3 \times 10^{-5}$, bearing in mind the type of aggregate used.

63. The type of aggregate is also a very important point. Mr Broad has mentioned his particular interest in Lytag. I would like to ask the Authors whether in the planning stages of the work any consideration was given to the type of aggregate used, because it seems to me that there would be considerable benefit from the choice of an 
aggregate with a low value of expansion and creep, and it would have given a more satisfactory behaviour.

64. In Fig. 141 was surprised that the Authors show that the majority of the concrete was found to swell and not to shrink. I am sure the Authors are aware that this evidence conflicts with the commonly accepted view and research by others to the effect that concrete shrinks as it dries. Can the Authors comment further on this point, especially in relation to the reliability of the method of temperature correction on which these results are based, and also the method used for making the shrinkage measurement?

65. Now that the Authors know the snags involved with this system, I should like to know their present opinions on the relative merits of this type of prestressed road and that where pretensioned wires are stretched between abutments. Pretensioned roads have the merit that there are no difficulties with creep of the concrete. They are also, I would say, preferable to the method which uses post-tensioned cables, in which there is difficulty with the cable friction. Pretensioned roads avoid both these difficulties. There are several good examples of pretensioned roads or pavings on airfields, notably roads in Holland and at Vienna airport.

\section{Dr R. H. H. Kirkham, Road Research Laboratory}

I should like to enquire about two points of detail. The first concerns the shrinkage measurements which were made in connexion with the road. It is surprising that most of the results show swelling, and that only $25 \%$ of the slabs show any shrinkage during the summer months. The Authors also refer to similar results obtained in connexion with other experimental work. I should like to know, however, whether in all the experiments to which they refer the concrete in the reference slabs was cured by a resin spray and whether they were untrafficked. In these circumstances, it is possible that the curing compound might remain and the moisture changes in the reference slabs, and consequently the shrinkage movements, might be less than those for the corresponding slabs in the road.

67. If, on the other hand, the evidence indicates that the measurements on the reference slabs indicate the conditions in the road, I wonder whether any estimate has been made of the variation in shrinkage strain through the depth of the slab. Generally in laboratory work the shrinkage is greater near the top surface as cast than near the bottom of the slab. Since there is also a differential loss of moisture when the slabs are cast in the ground, the differential shrinkage between the top and the bottom will be increased and although, as the results show, there may be little or no tensile strain due to shrinkage at the middle of the slab, the strains at the top may be considerable and could have an effect on early cracking.

68. The second point concerns the base used at Winthorpe, which was a 4 in. thickness of lean concrete laid on a 12 in. thickness of crushed stone, giving a total thickness of construction of 21 in. for the thinner prestressed slab. For conventional concrete construction a much thinner base would be used and the total depth of construction would be less. Was the thicker base considered necessary because of the higher loads likely to be imposed on the soil by the use of thinner, more flexible slabs? Such a thick base, if it is essential, would offset to a considerable degree any economy which might be achieved by the use of the thinner slabs which were prestressed.

69. I should like also to consider the question of the future of prestressed work. Experience at Winthorpe with quartzite gravel aggregate has shown that creep losses were sufficient to necessitate the re-application of the prestress four times in three years. This required closing the road for a period of two weeks each time, which would be unacceptable on a major road. With the 5 in. thick slabs also there must be the risk of compression failures; such failures have been reported in both Belgium and France and the Authors have indicated one minor failure on the road at Winthorpe. Although this might have been prevented by thicker dowels, as the Authors suggest, it would be difficult to include such dowels in these thin slabs. 
70. On the other hand it must be doubted whether the 7 in. thick slabs are likely to give economy. With this thickness the need for three or four restressings would, on the basis of the costs given in the Paper, offset the cost of the extra concrete and steel compared with conventional construction even when the cost of the closures is neglected. The fixed system of prestressing between abutments using gravel aggregate is therefore not attractive. I believe that in the airport at Algiers a limestone aggregate was used, and it has been suggested that such aggregates, with a low thermal coefficient, may be essential for this form of prestressing. Would the Authors agree that the type of aggregate should be limited with this form of prestressing from now on?

71. Finally it must be doubtful whether other forms of prestressing, although they may be attractive for airfields, will be economical forms of road construction. Internal prestress with either cables or tendons is likely to be expensive. Another disadvantage which has not yet been brought out is that in this type of work there are very large movements at the joints, which is a considerable disadvantage from the maintenance point of view. With the free system of internal prestress which uses elastic joints to follow the movement of the slab and maintain the prestress, sufficiently durable joints have not yet been made. I wonder whether the Authors would agree that the future of prestressing for road work may well depend on the development of this type of joint, and that until a satisfactory one is available further trials of prestressed concrete are not justified.

\section{Written contributions:}

\section{Mr J. Mitchell, Ministry of Public Building and Works}

The Ministry of Public Building and Works (Airfields), formerly Air Ministry Directorate General of Works, last laid prestressed pavements in 1956. New work carried out since then has indicated that plain concrete and reinforced concrete are more economical than prestressed, and the difference in cost has widened with improvements in paving machines. Now that the slip-form paver is being used for airfield pavements, prestressed concrete costs and speed of construction appear to be at a great disadvantage. The development is, however, being closely followed, and prestressed concrete has advantages where a thin slab, such as in strengthening by overlaying hangar floors, would keep to a minimum the reduction of headroom and alterations to the hangar doors.

73. In $\S 4$ the Authors give details of blocking the prestressing joints with cement mortar. It is noted from $\$ 25$ that restressing may have to be carried out an additional four or five times at later dates. Would the Authors give details of what arrangements have been made for cutting out the high-strength cement blocks without damaging the slabs, and at the same time maintaining whatever prestressing remains? In $\S 8$ the sub-grade is given as a silty sand with stones and classed as normal for purposes of design so that a recommended construction for this road would be a 9 in. thickness of reinforced concrete. Could the Authors give details of the CBR, modulus of sub-grade reaction, and height of water-table?

74. The characteristics of thin prestressed concrete slabs appear to make them suitable for very low value bearing foundations of about CBR2. There appears to be no information available on the effects of a thin flexible slab on a poor foundation. Have the Authors considered these effects and, if so, is a poor foundation, especially of a plastic nature, likely to have accumulative deformations after trafficking? This would result in a wavy surface or a slab weakened by being suspended between the high points. The first item of Table 1 refers to a 'trial section (R.C.) 9 in. thick and $150 \mathrm{ft}$ long'. Could details please be given of any recorded movements in relation to temperature changes and whether there was any indication of a time lag when compared with the slab expansion and contraction? 
75. In $\$ 12$ there is reference to the surface being sprayed by a plastic curing compound. Could the Authors give more details of this compound and whether curing included protecting covers? Since 1956, MPBW airfields have been laid in continuous reinforced concrete construction without joints except at points of change of direction. It was, however, found that curing compounds sprayed on the surface within ten minutes of completing finishing operations were inadequate without protecting covers remaining in place for four days in summer and seven days in winter. Where the slipform paver is used, protecting covers are provided for a minimum of one hour and then 1 in. thickness of constantly damp vermiculate is provided to give protection for the remainder of the period. Is it possible that the cracks which the Authors considered as inevitable $(\$ 3)$ could be stopped if curing was improved?

76. With regard to the ground anchorages described in $\S 3$, attention is drawn to the difficulties of this type of construction in soft or waterlogged ground where extensive excavations are likely to result in sumps for collecting water.

77. It has been noted with interest that in $\S 14$ details are given of $2-3 \%$ of the prestress being absorbed by friction in the dowel-bars, and in $\S 36$ a relationship of $63 \mathrm{lb} / \mathrm{sq}$. in. per ${ }^{\circ} \mathrm{C}$ is given for effects of change in temperature. Do the Authors consider that similar values occur in reinforced concrete and plain concrete slabs?

78. The view has been expressed that prestressed concrete construction is likely to be more suitable for airfields than for roads, because of the high point loads from aircraft, and also because a runway could easily be closed for restressing if the secondary runway was used. The MPBW older type of airfields were designed with the main runway in the direction of the prevailing wind and one or two subsidiary runways to allow for changes in wind direction. Modern jet aircraft are less susceptible to wind changes than their propellered predecessors and there are very few airfields in the world with parallel runways. In roadwork it is normally possible to close half a width while work is carried out on the remainder. The operators would not accept this condition on runways. New airfields are being designed with a single runway.

79. The following design requirements appear to limit the use of prestressed concrete for airfield pavements:

(a) extensive airfield lighting, including bars of light across the runway at about $190 \mathrm{ft}$ centres for the full length of the runway, as recently provided at the Abbotsinch (Glasgow) Airport, are now required; this would limit prestressing to short lengths;

(b) new airfield lighting fittings 8 in. dia. $\times 4$ in. thick are being developed for inserting in holes cut by core cutters; in a prestressed pavement it is difficult to carry out modifications which may be required in the future development of landing aids;

(c) any damage caused to the runway by aircraft landing or fires would be extensive and difficult to repair;

(d) the $150 \mathrm{ft}$ width of a runway and $75 \mathrm{ft}$ width of a taxiway require a number of longitudinal joints which for strengthening purposes must be linked with tie-bars or dowels; this necessitates the difficult task of stressing the full width at the same time; it is not certain what the effects are of prestressing in one direction only, so could the Authors advise on this point, and whether it would be affected by temperature changes?

(e) to avoid aquaplaning it is frequently necessary to groove the surface $\frac{1}{8}$ in. deep at 1 in. centres. Could the Authors comment on the possible effects of this notching in a thin slab?

\section{Mr A. N. Sparke, Concrete Limited}

My company constructed a prestressed road in our works in Essex in the summer of 1961 and while, in many respects, our methods and experience match the Authors', there are points of contention. 
81. The road is $400 \mathrm{ft}$ long and was cast and stressed in two $12 \mathrm{ft}$ wide strips, 4 in. thick. Concrete abutments were cast at each end of the road and $0.2 \mathrm{in}$. dia. wires at 35 in. centres were stretched between them. Tension was applied by extending each wire 33 in. with a 3 ton hand winch, and was released by cutting with wire cutters. The road is thus a pretensioned road, cast on the long line principle. The methods were simple and inexpensive and worked perfectly. The Authors' statement $(\$ 2)$ that 'the use of cables required a large labour force to apply prestress and it was expensive because of the high cost of prestressing steel; it did not appear therefore as worthy of further development' applies to post-tensioned road slabs, but not to the method described.

82. While appreciating the difficulties of cost comparison, the following is put forward as the cost of stressing a slab $400 \mathrm{ft}$ long $\times 12 \mathrm{ft}$ wide. It will be noted that:

(a) a continuous road would require one anchor every $400 \mathrm{ft}$;

(b) there is no 'large labour force'; two men ran out, anchored and stressed the wires comfortably in five hours.

Cost of one anchor . . . . . . . . . . . . $\begin{array}{lllll}£ 120 & 0 & 0\end{array}$

Cost of high tensile wire, including stressing . . . $\begin{array}{llll}70 & 0 & 0\end{array}$

$=7 s 3 d /$ sq. $\mathrm{yd}$.

$£ 190 \quad 0 \quad 0$

If one takes this up pro rata to a $500 \mathrm{ft}$ stretch of road 5 in. thick, the results are:

Cost of anchor block . . . . . $5 / 4 \times £ 120=£ 150 \quad 0 \quad 0$

Cost of high tensile wire. . . . $5 / 4 \times \frac{500}{400} \times £ 70=£ 110 \quad 0 \quad 0$

$=7 \mathrm{~s} 11 \mathrm{~d} / \mathrm{sq} . \mathrm{yd}$.

$£ 260 \quad 0 \quad 0$

This compares with the Authors' figure of $6 s 11 d /$ sq. yd in $\$ 25$, a figure which does not include the cost of end abutments. While the 'pretensioned' road requires an abutment at closer spacing than the Winthorpe road, the Essex abutment was only designed to take $250 \mathrm{lb} / \mathrm{sq}$. in. of road cross section, whereas it is inferred that the Winthorpe abutments were designed for $2400 \mathrm{lb} / \mathrm{sq}$. in. of road cross section. It should also be noted that at Essex the sloping bays to the anchors are not required.

83. The Essex road is used as a standing for lorries while being loaded with precast concrete units, and since 1961 has taken some 100000 tons of concrete in loads averaging 10 tons. Speeds are always under $10 \mathrm{miles} / \mathrm{h}$, but the road is subjected to braking and accelerating stresses by each lorry. The road has no transverse reinforcement and, as in the Authors' case, 'it was thought that the method of prestress would become unattractive if such a provision were necessary'. There is now a small amount of longitudinal cracking, although the cracks are closed and do not affect the efficiency of the road in any way. It is therefore very interesting that, although unreinforced, the Winthorpe road has appparently not cracked, because it would appear that what would really make a prestressed road unattractive is not the high cost of longitudinal tendons, if these were simply provided, but the cost of transverse stressing or reinforcement.

\section{Mr Kidd and Dr Stott}

At the time the experiments at Winthorpe began, there was a surge of continental enthusiasm for the method. The first runway at Maison Blanche, Algiers airfield, was five years old and was behaving satisfactorily. The French had built a second runway at Maison Blanche and the Belgians had built a runway at Melsbroek, Brussels airport, using the method. France and Belgium had each built experimental prestressed concrete roads of substantial length; the Belgian road had experienced a 
'blow-up' in 1961 which was attributed to the road being only $3.2 \mathrm{in}$. $(8 \mathrm{~cm})$ thick at the site of the blow-up where it thickened to form a joint. Since that time, Continental experience has not been too happy because the Belgian airfield and the French and Belgian experimental roads have also suffered blow-ups.

85. The road at Winthorpe has behaved well except for an uplifting at active joint 3. This joint first moved during a 'proving' test, when a prestress of about $1500 \mathrm{lb} / \mathrm{sq}$. in. was applied to the road by jacks; at this time there was a differential movement of about 0.2 in. with bending of the dowel bars so that this joint was left with a weakness. In September 1965 it became necessary in the programme of work to restress the road. At the time, the temperature in the slab was $16^{\circ} \mathrm{C}$ and the measured prestress was $1250 \mathrm{lb} / \mathrm{sq}$. in. During the restressing, half the blocking concrete had been removed when the other half failed and the joint rose into the air (see Figs 17 and 18). It is thought that this incident could have been avoided by (a) thicker dowel bars and $(b)$ a more careful procedure when moving blocking concrete from a road under high stress, e.g. placing jacks or blocking bolts immediately after the concrete is moved. This joint has now been cut out, remade and correctly replaced.

86. We would like to thank Mr Broad for his remarks about the use of a British light-weight aggregate in Belgium. M. Huyghe, the Belgian engineer responsible for the road at Lier, told us recently that he is measuring an annual creep loss of about $250 \mathrm{lb} / \mathrm{sq}$. in. and an annual maximum prestress of about $2000 \mathrm{lb} / \mathrm{sq}$. in. His road is three years old and will be restressed for the first time at the end of this year. He claims that he can make a profit using imported aggregates provided he can build more than $3 \mathrm{~km}$ of road. He is planning to lay $5 \mathrm{~km}$ of road prestressed by this method in the near future. Clearly, an aggregate such as Lytag has considerable advantages for this type of work.

87. Mr Brook mentioned the triangular slab type of 'elastic joint' by which the prestress can be kept fairly constant despite temperature changes, creep of concrete, etc. The French have had some success with this type and also with a joint which incorporates a rubber sack filled with compressed air. The problem with these mechanisms is durability and none has lasted for more than a few years so far. The values of $5.05 \times 10^{8} \mathrm{lb} / \mathrm{cu}$. in. for the modulus of elasticity and $10^{-5} /{ }^{\circ} \mathrm{C}$ for the coefficient of thermal expansion were obtained from concrete about 6 months old. The change of $\lambda E$ from 50 through 65 and now to $78 \mathrm{lb} / \mathrm{cu}$. in. per ${ }^{\circ} \mathrm{C}$ has taken place with time as the concrete has matured. The choice of a gravel aggregate was made deliberately to give the method a severe test; at the time, we hoped to have a further opportunity to try an aggregate with a lower coefficient of expansion, e.g. limestone. The use of a gravel aggregate has required us to restress more often than would be acceptable.

88. Mr Brook and Dr Kirkham have challenged the measurements of concrete swelling and Dr Kirkham has suggested that the curing compound might have remained on the reference slabs and prevented drying shrinkage. This view is contradicted by recent measurements of surface permeability made at Winthorpe using a $20 \mathrm{~cm}$ head of water which have shown little difference between the reference slabs with the greatest expansion and contraction as follows:

$68 \mathrm{micro}$ in./in. expansion, $7.50 \mathrm{ml} \times 10^{-6} / \mathrm{sq} . \mathrm{cm}$ per $\mathrm{s}$ flow

$70 \mathrm{micro}$ in./in. contraction, $5 \cdot 38 \mathrm{ml} \times 10^{-6} / \mathrm{sq}$. $\mathrm{cm}$ per $\mathrm{s}$ flow.

The average flow on the reference slabs was $5.35 \mathrm{ml} \times 10^{-6} / \mathrm{sq} . \mathrm{cm}$ per $\mathrm{s}$ and on the road was $0.74 \mathrm{ml} \times 10^{-6} / \mathrm{sq}$. $\mathrm{cm}$ per s so that the road surface was considerably less permeable than the reference slab. Therefore, drying shrinkage would be expected to be less on the road than on the reference slabs. No estimate has been made of the variation in shrinkage strain throughout the depth of the slab.

89. Dr Kirkham and Mr Mitchell have asked about the base. There was a lack of suitable filling material on site and the levels were made up with a 12 in. thickness 


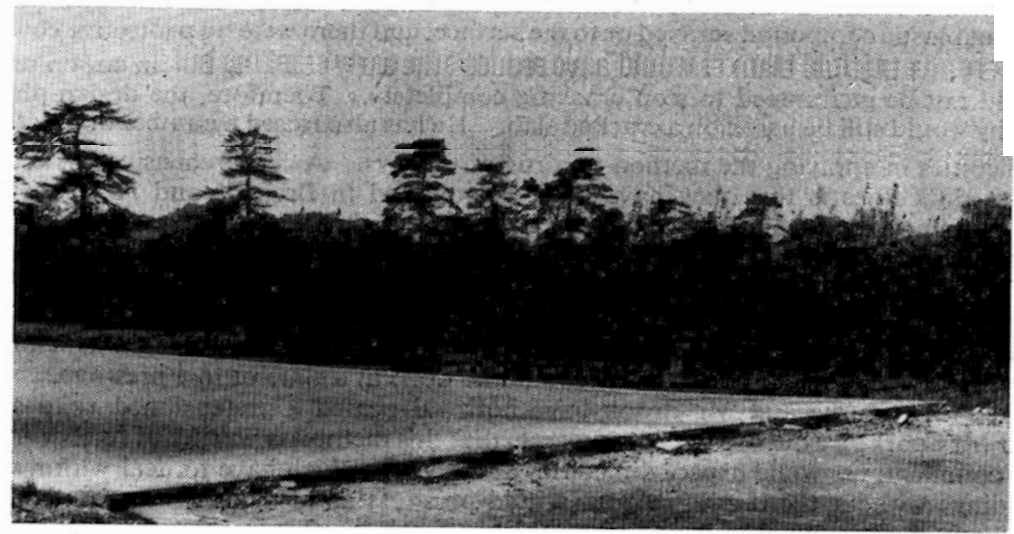

Fig. 17. View of active joint no. 3, after rising in air during restressing

Fig. 18. Clase-up of active joint no. 3 , showing bent dowel bars

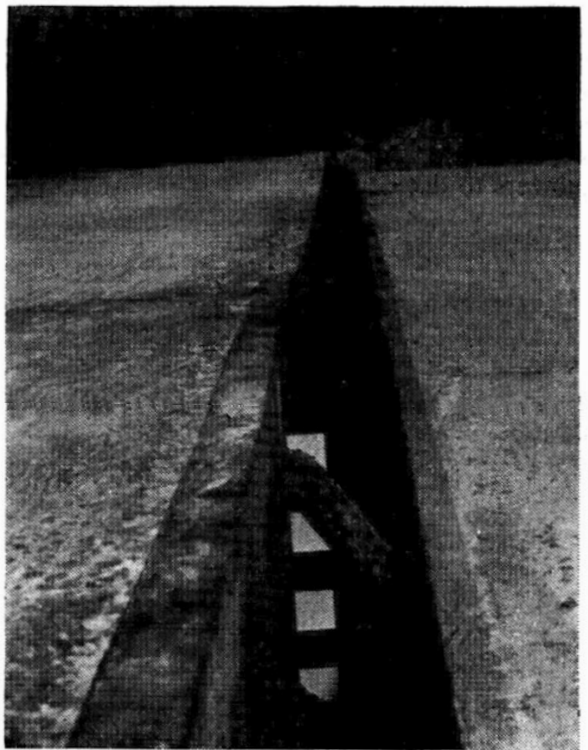

of crusher-run limestone on the site. This material had a modulus of subgrade reaction of about $130 \mathrm{Ib} / \mathrm{sq}$. in. per in. at the time of laying, which increased to about $380 \mathrm{lb} / \mathrm{sq}$. in. per in. after the slabs had been laid about 9 months. This was not regarded as a base in the sense of a 'strengthening' of the road. The underlying soil was a silty sand with stones (Casagrande classification $\mathrm{SF}-\mathrm{ML}$, remoulded CBR value 8-12) which was classed as 'normal' for purposes of design. The height of the water-table was about $4 \mathrm{ft}$ below ground level during the spring of the construction year; this varied over the site to some extent. 
90. Mr Mitchell has asked about the curing of the concrete; this was by a transparent plastic compound sprayed onto the surface, and there were no protective covers. Covers or a thermal blanket would have reduced the early cracking but, in our opinion, could not be guaranteed to stop cracking completely. Therefore, the design philosophy would still be based on a cracked slab. He has also raised a number of practical difficulties in applying the method to airfield runways. A comprehensive answer to these difficulties is that they have been surmounted in Brussels and Algiers. All single runway airfields have a common problem when extensive maintenance is needed, and at Brussels this has been met by using the taxiway as a temporary runway. Ducts for services can be laid under the pavement at the time of construction and grooving should not be detrimental provided the grooves are shallow-certainly an $\frac{1}{8}$ in. deep groove would be acceptable, or deeper grooves, e.g. for lighting cables, if properly back-filled. Such work should be done at a time of low prestress.

91. Mr Sparke and Mr Brook have both advocated a pretensioned road slab and Mr Sparke's evidence of costs suggests that this method is worthy of further trial. As comment, we would expect difficulties at the joints which have to deal with traffic loadings without the benefit of transmitted prestress as in the Winthorpe method; this consideration could require a slab thickness of 6 in. plus to accommodate dowel bars even with extra reinforcement at a joint. Also, the arrangement of anchorages needs development so that the prestressing does not interfere with laying the concrete.

92. Several people have asked what the future of the method might be. Our hope is that the success of the Winthorpe experiment may lead to further experiments, preferably with an aggregate of lower thermal expansivity than at Winthorpe. Such an experiment is, indeed, to be carried out by the Belgians in the near future. The method seems to be more applicable to airfields than to roads because loadings are heavier and maintenance supervision is easier. Perhaps it might be possible, therefore, to build an experimental airfield taxiway by the method: this is for some airfield engineers to decide. 